\title{
Mass Casualty Incident At Hospital Squadron Sipovo, Bosnia Following A Czech Hip Helicopter Crash, 8 Jan 1998
}

\author{
Lt Col D J Vassallo \\ RAMC* \\ Consultant General Surgeon
}

\author{
Sqn Ldr I D Sargeant \\ RAF \\ Consultant Orthopaedic Surgeon
}

Maj P J Sadler

RAMC

Consultant Anaesthetist

\section{Lt Col C J Barraclough \\ RAMC}

Consultant Anaesthetist

\section{Lt Col B M Bhatt}

RAMC

Consultant Physician

Hospital Squadron, 24 Armd Fd Amb, OP LODESTAR, Sipovo, BFPO 538

\section{Wg Cdr A C Wilcock \\ RAF}

Aeromedical Evacuation Co-ordination Officer

No.1 Aeromedical Evacuation Squadron, Divulje Barracks, Split, BFPO 544

SUMMARY: On Thursday 8 January 1998, a Czech Hip helicopter with 21 personnel on board crashed shortly after take off from Bos Krupa, northwest Bosnia. Seventeen casualties (including six with severe injuries) were airlifted from the scene for treatment at the British Hospital Squadron in Sipovo before aeromedical evacuation the next day to Prague, or discharge to their unit. This was the largest mass casualty incident dealt with by the British Defence Medical Services since British troops deployed to Bosnia in 1992.

\section{Introduction}

A Czech Hip helicopter crashed in Bosnia on 8 January 1998. This article details the role of the British Defence Medical Services in this incident.

\section{Setting}

The British Hospital Squadron at Sipovo, Republika Srpska, is located in the region of central Bosnia known as "the Anvil". It is the Role 3 medical facility for the Britishled Multi National Division South West (MND SW), established after the Dayton Peace Agreement of December 1995, as part of the NATO Implementation Force (IFOR) (Dec 95 - Dec 96) and then the Stabilisation Force (SFOR) (Jan 97 - Jun 98). The Hospital Squadron has superceded the smaller Medical Support Troops which existed as part of the United Nations Protection Force (UNPROFOR) between 1992 and 1996. The Hospital Squadron is drawn in turn from each of the three UK regular Field Hospitals and is attached to the Field Ambulance deployed in Bosnia for a period of six months. From October 97 to March 98, the Hospital Squadron in Sipovo was from 22 Field Hospital, Aldershot (with reinforcements from other units and the Royal Air Force), and attached to 24 Armoured Field Ambulance from Catterick.

The Hospital Squadron is staffed by two consultant-led surgical teams (general surgeon, orthopaedic surgeon, two anaesthetists, and operating theatre staff), a physician and two general duties medical officers, together with nursing, dental, laboratory, radiography, outpatient and physiotherapy staff. It is housed in Drash tents within a large factory building. The Resuscitation Department has two bays, with an overflow bay in an adjacent tent. There are three six-bedded wards. Another tent is normally used as a patients' rest area, but can be quickly converted into a 


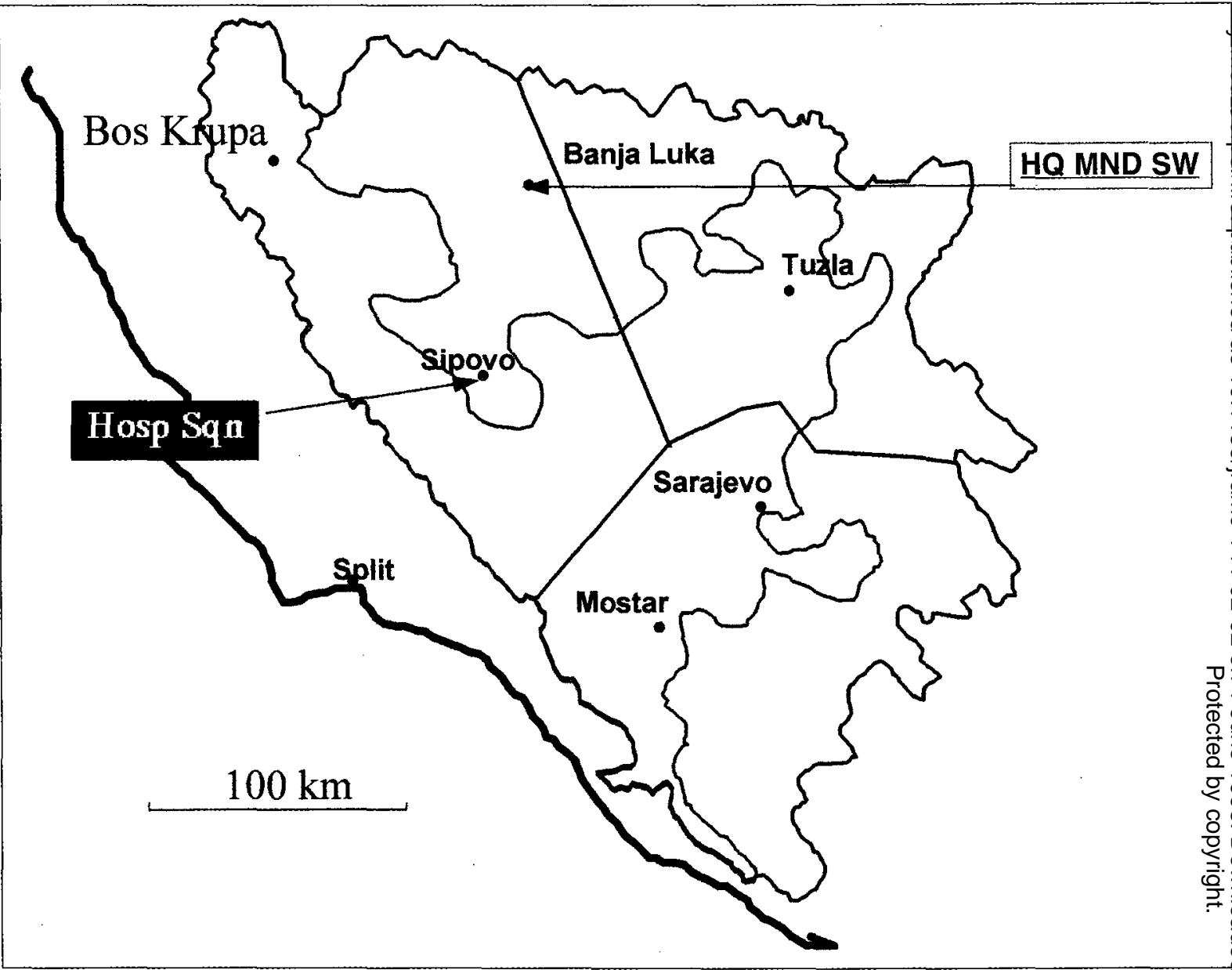

Bosnia, Jan 98.

fourth ward using stockpiled beds. The main operating theatre and two bedded intensive care unit are containerised units (GIAT, France), whilst the ancillary operating theatre is tented.

A Sea King Mark 4 helicopter, of B Flight, 845 Naval Air Squadron, is co-located with the Hospital Squadron. This Sea King is on 30 minutes notice to move as part of the Incident Response Team (IRT). The IRT was formed to provide rapid, efficient medical response to incidents where SFOR personnel have been injured. It is under direct control of HQ MND SW at Banja Luka. The IRT consists of pilots, loadmaster, consultant anaesthetist, operating theatre technician, aeromedic and a combat medical technician. A Royal Engineer Explosives Ordnance Disposal (EOD) team is also included because of the high mine threat. The team can be tailored to fit the demands of the incident.

\section{Scenario 1040 hrs 8 Jan 98}

Just before 1040 hrs on Thursday 8 January 1998, a
Czech Hip helicopter lifted off from the Czech SFOR camp at Bos Krupa, northwestern Bosnia, with 21 SFOR personnel (20 Czech and 1 British soldier) aboard According to eyewitness accounts, a loud twan suggestive of metal wires snapping was heard from the reare and the helicopter suddenly began spinning in a countere clockwise direction, throwing most of the personnel aboar towards the rear, except for the few with seatbelts. If crashed to the ground from a height of about 30 metres landing in the perimeter ditch of the camp 50 metres frong a known minefield, with the right hand side of thes helicopter taking the brunt of the impact. Burst fuel pipes sprayed the interior of the cockpit and the occupants with kerosene fuel. Whilst spinning out of control, the helicopte? knocked down the camp's main antenna, leaving it with minimal communications. The cause of the crash was latep established as tail rotor blade failure.

The overriding priority of the rescue personnel from the camp was to extricate the casualties from the wreckage before the leaking fuel could ignite. In a previous Hip crast 


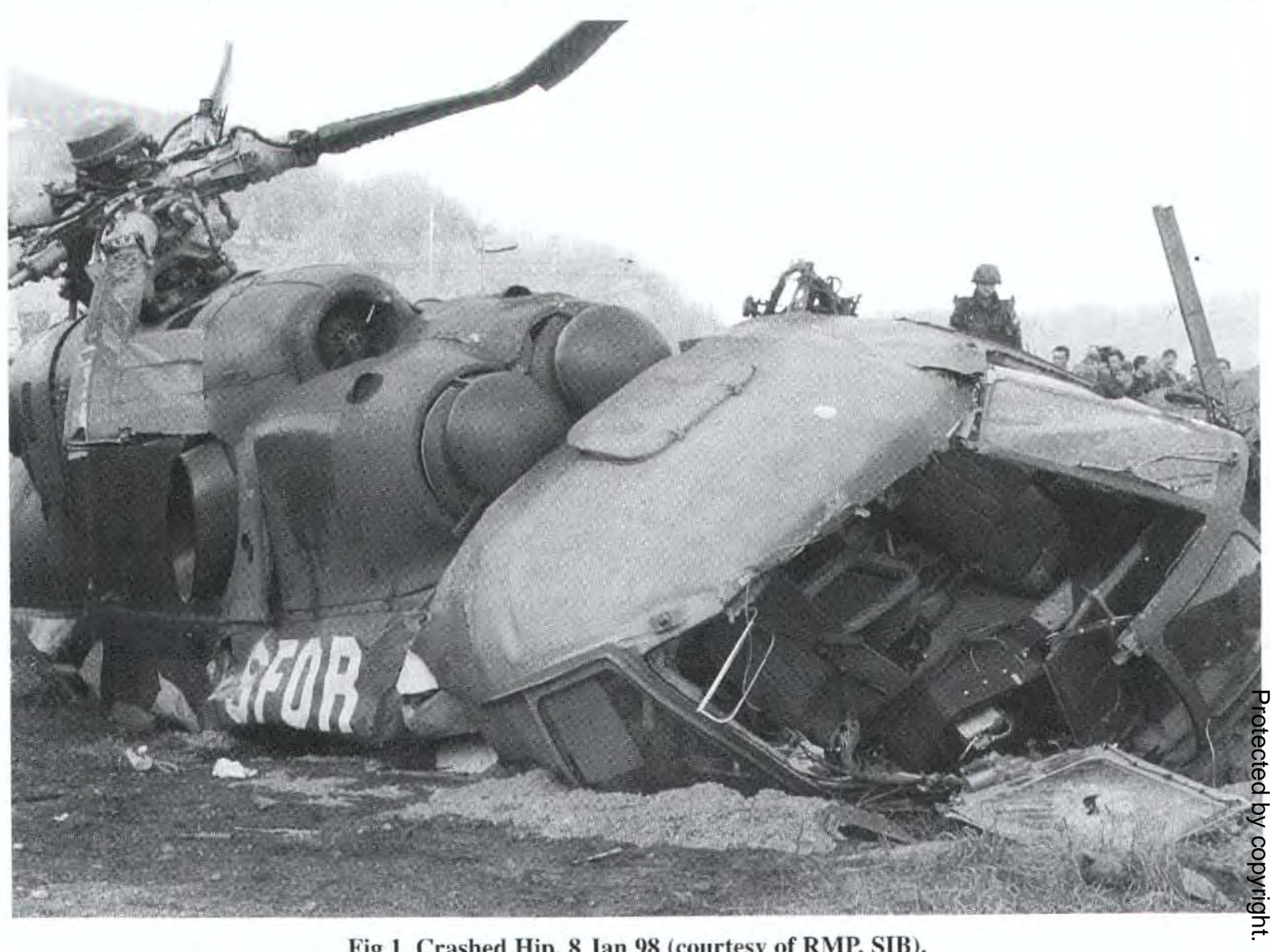

Fig 1. Crashed Hip, 8 Jan 98 (courtesy of RMP, SIB).

in Bosnia in September 1997, fire had engulfed that helicopter and there had been few survivors (Fig 1). Access to the helicopter was hazardous as the engine was still running and the main rotor blades were fragmenting as they hit the ground. The rescuers used metal-cutting equipment and saws to gain access to the cockpit, risking further injury to the occupants. Initial extraction was therefore rapid and emergency first aid was performed as soon as practicable.

HQ MND SW was notified of the crash by an Artillery bombardier using his personal radio, and tasked a medical section from Banja Luka, and the IRT from Sipovo. The IRT deployed at 1115 hrs. The Czech medical team on site, being unaware of the IRT's existence and faced with a large number of casualties, made the decision to evacuate by road to the local civilian hospital in Bihac. The British medical section aided in resuscitation of these casualties prior to the arrival of the IRT at $1145 \mathrm{hrs}$.

\section{Actions at scene and evacuation}

On arrival, the IRT found only the two most severely injured casualties remaining (the last extricated). They were assessed and treated according to Battlefield Trauma Life Support (BATLS) protocols including administering oxygen, establishing good intravenous access, commencing fluid resuscitation, and paying special attention to spinal immobilisation. Once stabilised, the casualties were loaded and transported by air to Sipovo. The Hospital Squadron was notified to expect two casualties and informed that all the others would be treated locally. The Czech medical team then realised that aeromedical transport to a SFOR location was available and began to relay the injured back to the crash site to await evacuation. The staggered arrival of patients at the scene and calls for further aeromedical evacuation led to confusion in relaying numbers of expected casualties via HQ MND SW to the Hospital Squadron. This progressive escalation of the incident led HQ MND SW to place other SFOR hospitals in Bosnia on standby (the American Hospital in Tuzla, the German at Sarajevo, the Canadian at Coralici and the Dutch at Novi Travnik) but to centralise all patients at Sipovo.

Following a further 3 trips by Sea King helicopters and 1 by a Chinook from 1310 Flight RAF from Split, 17 patients 0 (including six seriously injured) were admitted to Sipovo. $\mathbf{N}$ Four others were transferred elsewhere: two with minor fractures were treated by the Czech Field Surgical Team at Klisa, Eastern Slavonia, one with maxillofacial (Le Fort III) 
and neurosurgical trauma was transferred by Sea King from Bihac hospital to Zagreb, and another patient with minor injuries adamantly refused to board another helicopter.

\section{Timings of arrival at Sipovo}

The crash occurred at 1040 hrs. The first two casualties, both seriously injured and therefore Priority One (P1), arrived at 1250 hrs. The next two P1 casualties arrived at 1345 hrs after which, on notification of further casualties, a mass casualty situation was called. All off duty personnel were called in, and the emergency ward was opened up. A further P2 casualty followed at 1530 hrs, eleven P3 casualties arrived by Chinook at 1545 hrs, and finally a P2 casualty with spinal trauma arrived at $1635 \mathrm{hrs}$. All P1 and P2 casualties arrived by Sea King accompanied by either an anaesthetic team or RAF medics.

\section{Resuscitation}

BATLS guidelines were followed with trauma teams of a doctor, nurses and combat medical technicians assigned to each patient in the Resuscitation department. Because of the nature of the crash, with the patients sustaining a combination of severe rotational, vertical and horizontal deceleration stresses, particular attention to spinal immobilisation was maintained until spinal injury was excluded by both clinical and radiological examination.

\section{Case Summaries: P1 \& P2 Injuries (in order of arrival)}

\section{Patient 1}

The co-pilot. He was seated on the right hand side of the cockpit, therefore taking the brunt of the impact. His injuries consisted of closed fractures of the right foot, right tibia, right femur, disruption of the pubic symphysis and right sacroiliac joint, fractured first lumbar vertebra, seatbelt contusions to upper abdomen, bilateral lung contusions and haemothoraces. Bilateral chest drains were inserted. He underwent manipulation under anaesthesia of his tibial fracture and application of Thomas splint traction.

\section{Patient 2.}

$\mathrm{He}$ had a fracture of the right first rib and an underlying haemothorax. He was cyanosed at the scene. His condition improved with oxygen during transfer and stabilised once a chest drain was inserted in Resus. Sixteen hundred mls of blood drained through over this over the next 18 hours.

\section{Patient 3.}

$\mathrm{He}$ had a posterior dislocation of the right hip. He was transferred to the operating theatre for reduction under sedation.

\section{Patient 4.}

He had seatbelt contusions over the right flank. He was suspected of having spinal injuries, without neurological deficit. X-rays confirmed that he had an unstable fracture of the odontoid peg (Fig 2), a crush fracture of the 12th

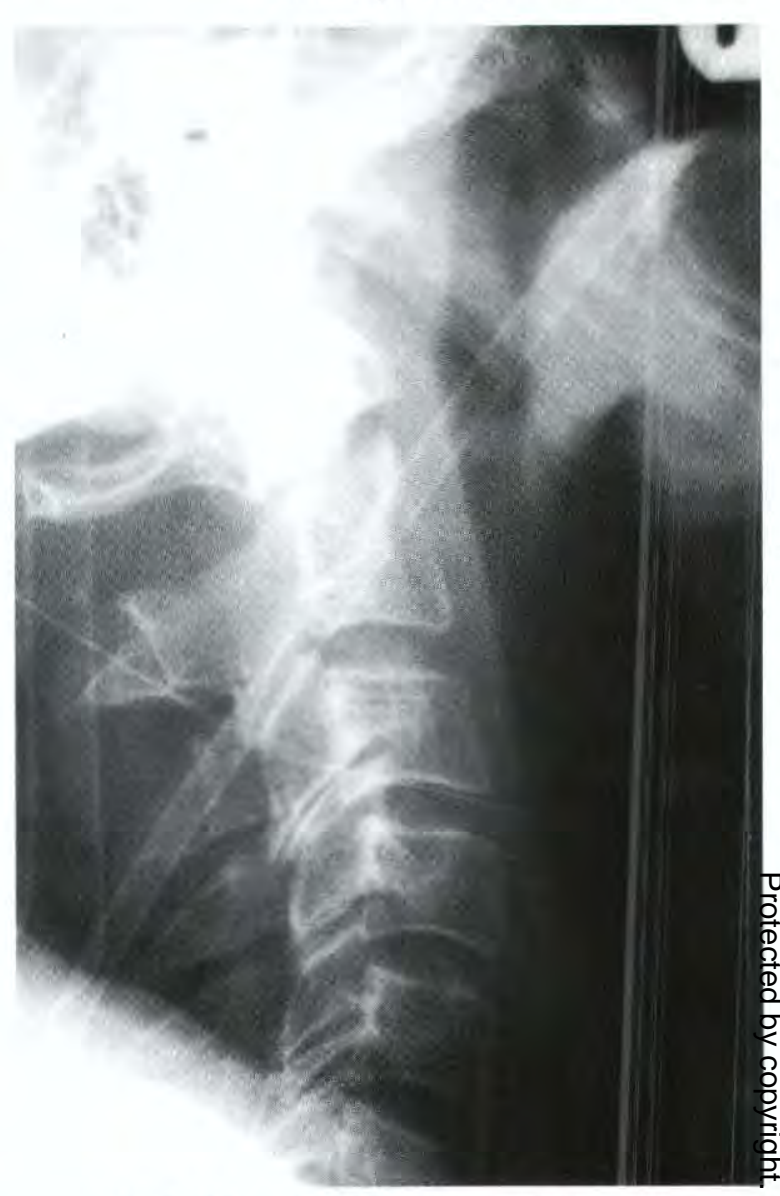

Fig 2. Odontoid Peg Fracture, Patient 4.

thoracic vertebra, and a fractured right lower rib. He was therefore maintained in rigid spinal immobilisation.

\section{Patient 5.}

He had a severely displaced fracture of the left lower humerus, a fracture of the surgical neck of the same humerus, marked seatbelt contusions over abdomen and left chest, and a lateral scleral tear. His arm injury was treated by plaster immobilisation.

\section{Patient 6}

He had a compression fracture of the 8th thoracic vertebra.

\section{P3 Injuries}

The eleven P3 casualties were promptly examined and triaged on arrival. They were re-examined twice later on the ward. At each examination, further injuries were discovered. Seven fractures (fibula, olecranon, ribs, scaphoid, finger, maxilla and mandible), one kerosene contact burn to buttocks, and a variety of soft tissue bruises and lacerations were identified. 


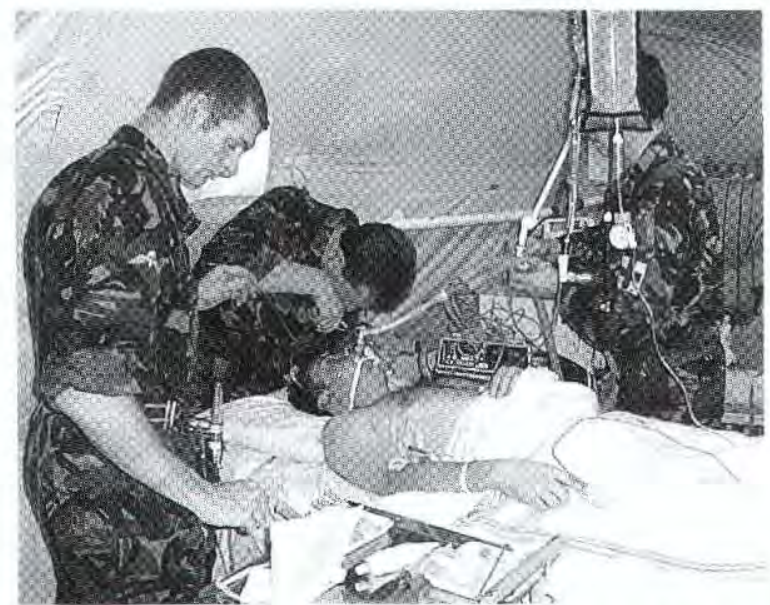

Fig 3. Stabilisation of Polytrauma Patient Prior to Aeromed.

\section{Aeromedical evacuation}

The six stretcher patients required aeromedical evacuation for definitive surgery or long term hospitalisation. It was decided that this would be best achieved by repatriation to the Czech Republic. A Czech Antonov plane with surgical and anaesthetic teams from the Central Military Hospital, Prague was tasked and arrived at Banja Luka airfield 1030 hrs, Friday 9 Jan. On confirmation that it had landed, a Sea King transferred Patient 4 (odontoid peg fracture) accompanied by our orthopaedic surgeon. At 1230 hrs, a Chinook transferred stretcher Patients 2,3,5 and 6 on a unique aeromedical lift.

Patient 1, with polytrauma, had deteriorated overnight and was requiring higher oxygen concentrations (Fig 3 ). For safe transfer he was electively intubated, ventilated, and invasively monitored with arterial and CVP lines. To minimise his time in transit and to allow the medical team to assess the facility of the onward transport to Prague, he was transferred last, accompanied by a full anaesthetic team, on a SeaKing at 1358 hrs.

All P1 and P2 casualties were accompanied by full discharge summaries, translated into Czech by a Czech doctor who had arrived with the P3 casualties and stayed on as interpreter and liaison officer for the Czech authorities.

The Czech Antonov left for Prague at $1455 \mathrm{hrs}$. At the same time the Chinook transported the 10 Czech P3 casualties back to their own medical facility at Bos Krupa. This left the sole British P3 casualty (with a fractured finger and bruised leg) at the Hospital Squadron.

The total time from the crash to departure of the last Czech patients from Hospital Squadron was 28 hours 15 minutes.

\section{Discussion}

This region of Bosnia is mountainous and the roads are poor. Appropriate surgical facilities are widely separated. The use of the aeromedical helicopters to retrieve and evacuate casualties to definitive care is fundamental to SFOR medical planning. Their effective use in this incident confirms previous experience in this theatre (1).

The injuries were caused by a combination of complex linear and rotational decelerational forces, unrestrained occupants impacting on items of cabin equipment, and restrained occupants being crushed by the collapsing cabin structure. It is difficult to attribute any one injury to a particular force.

The severe rotational forces before ground impact caused unrestrained occupants to be thrown to the back of the aircraft, flailing against various structures, hence the broad pattern of injuries of the P3 casualties. These rotational forces possibly accounted for an unusual pattern of ocular trauma: four patients had an identical, well circumscribed right sided subconjunctival haematoma with its apex at the lateral tether of the eyeball. It has been suggested that horizontal deceleration forces, -Gx, (due to forward movement on impact with the ground) predispose to head. cervical and upper thoracic injuries (as seen in Patients $1,2,4$ ) and that vertical deceleration forces, $+\mathrm{Gz}$, (as a result of dropping from a height), predispose to thoraco-lumbar fractures in upright, seated occupants (seen in Patients $1,4,6)(2,3)$. It has also been shown that helicopter pilots are particularly prone to foot and tibial fractures through longitudinal forces transmitted through the foot pedals oro impact (seen in Patient 1)(4).

The high proportion of spinal injuries ( 3 out of 21 , o $14 \%$ ) is consistent with previous reports of survivable o partially survivable helicopter crashers $(2,3,5)$. Patient 4 with the odontoid peg fracture but no neurological deficito illustrates the necessity for careful neck evaluation trauma patients, as was demonstrated in another survivo from a helicopter crash in the Gulf War (6).

No passenger was wearing a helmet, a common practice in Bosnia. This lack of head protection probably accounted for the severity of the maxillofacial and neurosurgical trauma in the patient flown to Zagreb, and for the multitude of facial lacerations and bruising in the patients treated at Sipovo. It has been shown that non-helmeted helicopter occupants in, at least, partially survivable accidents are at significantly higher risk of severe or fatal head injuries than helmeted occupants $(3,5,7,8)$. There has also been one recent, well-publicised case in Northern Ireland where the wearing of a helmet saved a soldier from death when he walked too close to a spinning tail rotor (9). Wearing : helmet should be made mandatory for all personnel on helicopter flights.

There were no intra-abdominal injuries, a result similar to that of a study of US Army helicopter crashes (3). The only abdominal injuries in this incident were superlicial contusions and abrasions secondary to seat belt restraints in three patients (Patients 1, 4 and 5). The restraints may account for the spinal fractures in two of these (Patients $1,4)$.

The variety of injuries sustained by the P 3 casualties, and especially that several were missed on first examination, illustrates the need to be vigilant with such patients. It is all 
too easy to be distracted by the more obvious wounds in a mass casualty situation, when it is often the missed "minor" injuries that cause the greatest morbidity in the long term.

It was fortunate that fire did not break out as $40 \%$ of fatalities in survivable crashes are due to thermal injury (3).

There was minimal British press coverage of this incident in its immediate aftermath, with a fleeting reference to the insignificant injuries sustained by the British P3 casualty (10). This highlighted the need for a more robust approach to proactive reporting of the operational activities of the Defence Medical Services.

Prior to deployment to Bosnia, all medical unit personnel underwent BATLS and Battlefield Advanced Resuscitation Techniques and Skills (BARTS) training. This is modelled on Advanced Trauma Life Support (ATLS) training and was introduced to the UK in 1987 by the late Brigadier Ian Haywood (then Professor of Military Surgery), undergoing its baptism of fire in the Gulf War (11). In theatre, an intensive in-house BATLS training programme modelled on the Gulf War experience (consisting of lectures, skill stations, and casualty simulation exercises) did much to boost the confidence of all staff. The value of this training was illustrated by the efficient treatment of casualties throughout this incident.

\section{Conclusion}

This helicopter crash resulted in the largest mass casualty incident involving peacekeepers in Bosnia since war broke out in Bosnia in 1992. The successful management of this incident by the British Defence Medical Services, primarily personnel from 24 Armoured Field Ambulance and the Hospital Squadron from 22 Field Hospital, together with the RAF and RN members of the Aeromedical Evacuation Squadron, reflects very highly on the standard of training and preparation of our personnel.

\section{Acknowledgments}

To Angela Savory, Assistant Librarian at the Royal Surrey County Hospital, Guildford, who Emailed the literature search request on helicopter crashes to the Hospital Squadron, and to Michael Rowe, Librarian at the Royal Hospital Haslar, for similar Emails.

To Dr George (Jiri) Brancik, Czech psychologist, for his sterling assistance as a colleague, as an interpreter and as liaison officer between Hospital Squadron and the Czech authorities during this incident.

\section{Editors Note}

from Army Medical Directorate

The writer did not appreciate that a reporting embargo was placed on this incident until the Board of Inquiry had announced their decision. Hence only a fleeting reference to the incident in the media. This is normal in such an accident, it stops specualtion.

\section{REFERENCES}

1. DAshfield AK, SMith HR, Young PC. "Operational Medicine. Aeromedical evacuation in Bosnia". IR Nav Med Serv 1997; 83(1):8-13.

2. Scullion JE, Heys S D, Page G. "Pattern of injuries in survivors of a helicopter crash". Injury 1987;18:13-14.

3. Shanahan DF, Shanahan MO. "Injury in U.S. Army Helicopter Crashes October 1979 - September 1985". J Trauma 1989; 29:415-423.

4. Dummit ES, ReID RL. "Unique tibial shaft fractures resulting from helicopter crashes". Clin Orthop 1969: 66:155-158.

5. VYRNWY-JONES P, THORNTON R. "Helicopter accident survivability". J R Army Med Corps 1984; 130:1500음 156.

6. Chaudhri K, Crbulski GR, Pitkethly DT, Al Hem B, Johnson MC. "Multiple cervical spine fractureg without neurologic deficit after a helicopter crash Case report". Spine 1993; 18:2135-2137.

7. VyRnWY-Jones P. "A review of Army Air Corp? helicopter accidents 1971-1982". Aviat Space Enviroł Med 1985; 56:403-409.

8. CROWLEY JS. "Should helicopter frequent flyers wear head protection? A study of helmet effectiveness. J Ocup Med 1991; 33:766-769.

9. Gibbons JR, Orr L, Carr DJ, Gibbons CER. ̄̄ "Helicopter main rotor blade injury to the head with survival". . I R Army Med Corps 1997; 143:122-123.

10. Daily Telegraph, 1998; January 9:19.

11. Ruley B, MAHONEY P "Battlefield Trauma Life Support: Its use in the Resuscitation Department of 32 Field Hospital during the Gulf War". Milit Med 1996; 9:542 546. 